\title{
Cyclooxygenase Isoenzyme-2 and Vascular Endothelial Growth Factor are Associated with Poor Prognosis in Esophageal Adenocarcinoma
}

\author{
M. J. D. Prins • R. J. J. Verhage • F. J. W. ten Kate • \\ R. van Hillegersberg
}

Received: 17 October 2011 / Accepted: 28 December 2011 /Published online: 19 January 2012

(C) The Author(s) 2012. This article is published with open access at Springerlink.com

\begin{abstract}
Background Cyclooxygenase isoenzyme-2 (COX-2) and vascular endothelial growth factor (VEGF) contribute to angiogenesis and are overexpressed in various malignancies. The aim of the study was to evaluate expression, prognostic value and correlation between COX-2 and VEGF expression in esophageal adenocarcinoma (EAC).

Methods Surgical specimens of 154 patients with EAC were used to construct a tissue micro array (TMA). TMA sections were immunohistochemically stained for COX-2 and VEGF and scored on intensity of staining.

Results Estimated 5-year cancer specific survival was 37\%. High COX-2 and VEGF expression was observed in 39 (26.5\%) and in $77(53.8 \%)$ tumors, respectively. Both markers were associated with poor cancer specific survival $(p=.022$ and $p=.004$, respectively, log rank). No significant correlation was found between VEGF and COX-2 expression $(r=063$; $p=.455$ ). In multivariate analysis, high COX-2 expression (HR $1.65 ; 95 \%$ CI $1.04-2.61 ; p=.034$ ) was associated with overall survival. In patients with $\mathrm{T} 3$ tumors, COX-2 expression was an independent prognostic factor for cancer specific survival (HR 1.81 95\% CI 1.10-2.95; $p=.019$ ).

Conclusions This is the first study that evaluated the prognostic value and correlation of COX-2 and VEGF expression in a large and homogenous population of patients with EAC. No correlation between COX-2 and VEGF expression was found. Both markers were expressed in EAC and were associated with poor prognosis. The findings support the use of COX-2 and VEGF inhibitors in future clinical studies.
\end{abstract}

Keywords Esophageal cancer-Adenocarcinoma .

Esophagectomy $\cdot \mathrm{COX}-2 \cdot \mathrm{VEGF} \cdot$ Survival

\section{Introduction}

Worldwide, esophageal cancer is the 7th leading cause of cancer death. ${ }^{1}$ Advancements in diagnostics, surgical techniques, and the application of neoadjuvant chemotherapy

M. J. D. Prins • R. J. J. Verhage • R. van Hillegersberg $(\bowtie)$ Department of Surgery, University Medical Center Utrecht, P.O. Box 85500, 3508 GA, Utrecht, The Netherlands e-mail: R.vanHillegersberg@umcutrecht.nl

F. J. W. ten Kate

Department of Pathology, University Medical Center Utrecht, Utrecht, The Netherlands have improved survival rates. Studies report 5-year survival rates of up to $40 \%$ for patients with resectable disease. ${ }^{2-4}$ Further therapeutic improvements are warranted and the focus is now turning to targeted therapy. This has led to an increasing interest in the prognostic and therapeutic value of biological tumor markers that are known to play a key role in carcinogenesis and progression. Markers which can be selectively blocked with pharmaceuticals are of particular interest. $^{5-7}$ Two of these biomarkers, cyclooxygenase-2 (COX-2) and vascular endothelial growth factor (VEGF), may play a significant role in esophageal adenocarcinoma (EAC).

COX-2 is the rate-limiting enzyme involved in the conversion of arachidon acid to eisosanoids such as prostaglandin (PG), prostacyclin and tromboxanes. Its expression is induced by several stimuli including growth factors, inflammation, and cytokines. Overexpression of COX-2 is reported in many human malignancies such as colon, ${ }^{8}$ 
gastric, ${ }^{9}$ pancreas, ${ }^{10}$ lung, ${ }^{11}$ breast carcinoma, ${ }^{12}$ and also in esophageal cancer. $^{13,14}$

The VEGF gene family belongs to the platelet-derived growth factor (PDGF) gene and encodes for VEGF-A, B, C, $\mathrm{D}, \mathrm{E}$, and placenta growth factor (PIGF). VEGF-A, referred to as VEGF, is the most potent endothelial cell specific mitogen that induces angiogenesis, which is critical to both tumor growth and systemic spreading of tumor cells. ${ }^{15}$ High VEGF expression is reported in several malignancies, including esophageal cancer. ${ }^{13,16-19}$

A relationship between COX-2 and VEGF has been described earlier. ${ }^{20,21}$ COX-2 generated PGs contributed to angiogenesis through the induction of VEGF. Moreover, it was demonstrated that COX-2 inhibition (e.g., with the use of diclofenac, rofecoxib, or celecoxib) resulted in both COX-2 and VEGF protein downregulation. These findings suggest that COX-2 and VEGF expression are interlinked. ${ }^{2,23}$

The role of COX-2 and VEGF and their interaction in EAC is yet unclear. The aim of this study was to evaluate expression and prognostic significance of COX-2 and VEGF in adenocarcinoma of the esophagus. Furthermore, the correlation between COX-2 and VEGF protein expression in EAC was evaluated.

\section{Materials and Methods}

\section{Study Population}

All patients who underwent esophagectomy for cancer between August 1988 and November 2009 at the University Medical Center Utrecht were collected in a database. Patients with histologically proven EAC were included. Patients with esophageal squamous cell carcinoma (ESCC), neoadjuvant treatment, pathological T4 disease, distant metastases, tumor positive resection margins (R1) according to the College of American Pathologists (CAP) criteria, ${ }^{24}$ and patients who died in-hospital or within 30 days from operation were excluded from the study.

All tumor resection specimens were reviewed by an experienced pathologist (FJWtK). Tumors were staged according to the TNM staging system (7th edition). ${ }^{25} \mathrm{~A}$ follow-up study was performed in which patients were followed up until death or up to July 2011. Follow-up data were collected with the use of chart examination, general practitioners archives, and the Dutch Cancer Registry.

Primary outcome was the percentage of COX-2 and VEGF expression. Secondary outcomes were the correlation between COX-2 and VEGF expression as well as cancer specific survival (CSS; defined as the time between surgery and death due to cancer) and overall survival (OS; defined as the time between surgery and death). The study was performed in accordance with the local ethical guidelines concerning informed consent using patient's material after surgical resection.

\section{TMA Construction}

Formalin-fixed, paraffin-embedded tumor blocks were used for construction of a tissue micro array (TMA) as described earlier by Boone et al. ${ }^{13}$ Briefly, for each tumor specimen, three representative regions were marked on the pathological hematoxylin and eosin-stained slide. These regions, referred to as tumor cores, were punched out and placed into the TMA paraffin block.

\section{Immunohistochemistry}

From the TMA, 4- $\mu \mathrm{m}$ sectioned slides were deparaffinized in xylene (15 min) and dehydrated in serial ethanol dilutions (15 min). Between all steps, tumor slides were rinsed with Tris- $\mathrm{HCl}$ buffered saline $\mathrm{pH} 7.4$ (TBS). The endogenous peroxide activity was blocked by hydrogen peroxidase $(0.3 \%)$ methanol solution for $20 \mathrm{~min}$. Antigen retrieval was achieved by boiling the slides for $10 \mathrm{~min}$ in $0.01 \mathrm{~mol} /$ L sodium citrate ( $\mathrm{pH}$ 6.0). Then TMA slides were incubated during $60 \mathrm{~min}$ in blocking solution (contents: $0.1 \mathrm{~mol} / \mathrm{L}$ Tris- $\mathrm{HCl} \mathrm{pH} 7.4 ; 1 \mathrm{~mol} / \mathrm{L} \mathrm{MgCl2}$; Tween-20; 10\%BSA; Goat serum and $\mathrm{H} 2 \mathrm{O}$ ) to block unspecific binding sites. Subsequently, TMA slides were incubated with COX-2 monoclonal antibody (Cayman Chemical, Catalog\#160112, Clone CX229, dilution 1:100), overnight at $4^{\circ} \mathrm{C}$. The next day slides were rinsed with TBST (Tris- $\mathrm{HCl}$ buffered saline pH 7.4 with Tween-20) and post-antibody blocking solution (not diluted) was added for $15 \mathrm{~min}$. Subsequently, slides were incubated with polyclonal Goat-anti-Mouse/Rabbit/ Rat IgG (not diluted) during $30 \mathrm{~min}$. Peroxidase staining was visualized with 3-amino-9-ethylcarbazole solution and slides were counter stained with hematoxylin (10 s).

For VEGF staining, tumor slides were deparaffinized in xylene (15 $\mathrm{min})$ and dehydrated in serial ethanol dilutions (15 min). Between all steps, slides were rinsed with phosphate buffered saline $\mathrm{pH}$ 7.4. The endogenous peroxide activity was blocked by hydrogen peroxide (3\%) for $15 \mathrm{~min}$. Antigen retrieval was achieved by boiling the slides for $20 \mathrm{~min}$ in sodium citrate ( $\mathrm{pH}$ 6.0). After a cooling off period (20 min), the slides were incubated with polyclonal $\mathrm{VEGF}_{165}$ antibody (R\&D Systems, Catalog\#AF293NA, dilution 1:50) for $60 \mathrm{~min}$ at room temperature. Subsequently, TMA slides were incubated with biotinylated secondary Rabbit-anti-Goat antibody (1:50) for $30 \mathrm{~min}$. Slides were treated with Strep AvidinBiotin complex for $30 \mathrm{~min}$ and peroxidase staining was visualized using 3,3'-diaminobenzide for $10 \mathrm{~min}$. The sections were counterstained with hematoxylin (10 s).

For positive controls, colon and stomach carcinoma (known to express high COX-2 protein) were included and 
a Grawitz tumor as positive control for VEGF staining. Non-cancerous esophageal squamous cell epithelia were used for internal control. Negative controls were achieved by omitting the primary antibody.

Immunohistochemical Scoring

Immunohistochemical scoring was performed by FJWtK. Cores were considered lost if less than $10 \%$ of the tissue contained tumor (i.e., sampling error), less than $10 \%$ of tissue was present (i.e., absent core), or when two out of three cores were lost. The scoring of VEGF and COX-2 expression was based on the intensity of staining, which ranged from 1 (no staining), 1 (weak), 2 (moderate), and 3 (strong staining). The lowest observed staining score for COX-2 was 1 . At least one tumor core had to have a score of 3 to be considered as high COX-2 staining. The highest scoring intensity observed in VEGF stained cores was 2 . For VEGF, the median score of the sum of the two highest cores was calculated and used as a cutoff value. Tumors which scored $<1$ were defined as low VEGF expression and tumors which scored $\geq 1$ as high VEGF staining.

\section{Statistical Analysis}

Association between clinical parameters and COX-2 and VEGF staining were evaluated using cross tabulation (Pearson's chi-square test). Survival rates were estimated by using the Kaplan-Meier function (log rank test) to compare the OS and CSS among patients with high versus low COX2 and VEGF expression. Correlation between COX-2 and VEGF expression (dichotomous values) was evaluated using the Pearson's correlation.

The following parameters were evaluated in univariate analysis: T-stage (T1 or T2 vs. T3), lymph node metastases (no vs. yes), differentiation grade (good and moderate vs. poor), COX-2 (low vs. high), lymph node ratio ( $\leq 25 \%$ vs. $>25 \%$ ), vasoinvasion (no vs. yes), perineural growth (no vs. yes), VEGF (low vs. high), median age ( $<64$ vs. $\geq 64$ years), gender, and perinodal extension (no vs. yes). Variables that were significant in univariate analysis were included in multivariate analysis (Cox proportional hazards regression analysis). A $p$ value of $<.050$ was considered statistically significant. All analyses were performed using standard statistical software (SPSS version 15.0; SPSS Inc., Chicago, Illinois).

\section{Results}

Between 1988 and 2009, 290 patients underwent esophageal resection for EAC at the Department of Surgery of the University Medical Centre Utrecht. Patients with tumor

positive resection margins (R1; $n=26)$, with $\mathrm{T} 4$ disease $(n=7)$, patients who were pretreated $(n=49)$, and patients whose clinical and/or pathological data were incomplete or missing $(n=54)$ were excluded.

In a total of 154 patients, the female to male ratio was 1:4.5 with a median age of 64.0 years (range, 33.8-81.3). Lymph node metastases were observed in $104(67.5 \%)$ patients of which $62(59.6 \%)$ patients had perinodal extension (i.e., extra capsular location of tumor cells). A lymph node ratio (i.e., the number of positive nodes divided by the total number of resected nodes) of $>25 \%{ }^{24}$ was observed in $48(31.2 \%)$ patients.

Follow-up was complete in 144 (93.5\%) patients with a median follow-up of 26.4 months (range 2.7-260.3). Estimated 5-year CSS was 37\% (median CSS 30.4 months). All patient and tumor characteristics are summarized in Table 1.

Table 1 Baseline characteristics $(n=154)$

\section{LNN lymph nodes}

${ }^{\text {a }}$ Data are $n(\%)$, unless noted otherwise

${ }^{\mathrm{b}}$ Tumors were staged according to the TNM classification (anatomical stage groups, 7 th edition)

${ }^{\mathrm{c}}$ In 4 cases resection specimen did not contain lymph nodes. Median number of resected lymph nodes was 13 (range 0-70)

${ }^{\mathrm{d}}$ As a proportion of patients with lymph node involvement $(n=104)$

\begin{tabular}{|c|c|}
\hline & $n(\%)^{\mathrm{a}}$ \\
\hline \multicolumn{2}{|l|}{ Gender } \\
\hline Male & $126(81.8)$ \\
\hline Female & $28(18.2)$ \\
\hline \multicolumn{2}{|l|}{ Age (years) } \\
\hline Median (range) & $64.0(33.8-81.3)$ \\
\hline \multicolumn{2}{|l|}{ Type of resection } \\
\hline Transthoracic (open) & $24(15.6)$ \\
\hline $\begin{array}{l}\text { Transthoracic } \\
\text { (scopic) }\end{array}$ & $24(15.6)$ \\
\hline Transhiatal (open) & $105(68.2)$ \\
\hline Unknown & $1(0.6)$ \\
\hline \multicolumn{2}{|l|}{ Tumor stage $^{\mathrm{b}}$} \\
\hline $\mathrm{I} A B$ & $25(16.2)$ \\
\hline II $\mathrm{AB}$ & $24(15.6)$ \\
\hline III $A B$ & $69(44.8)$ \\
\hline III C & $32(20.8)$ \\
\hline Unknown & $4(2.6)$ \\
\hline \multicolumn{2}{|l|}{ Tumor extend ( $\mathrm{T}$ stage) } \\
\hline $\mathrm{T} 1$ & $17(11.0)$ \\
\hline $\mathrm{T} 2$ & $35(22.7)$ \\
\hline $\mathrm{T} 3$ & $102(66.2)$ \\
\hline \multicolumn{2}{|l|}{ LNN involvement } \\
\hline Yes & $104(67.5)$ \\
\hline No & $46(29.9)$ \\
\hline Not present ${ }^{\mathrm{c}}$ & $4(2.6)$ \\
\hline \multicolumn{2}{|l|}{ LNN ratio $>25 \%$} \\
\hline Yes & $48(31.2)$ \\
\hline No & $102(66.2)$ \\
\hline Unknown $^{\mathrm{c}}$ & $4(2.6)$ \\
\hline \multicolumn{2}{|l|}{ Perinodal extension $^{\mathrm{d}}$} \\
\hline Yes & $62(59.6)$ \\
\hline No & $42(40.4)$ \\
\hline
\end{tabular}




\section{COX-2 Expression}

Tumor cores of 147 (95.5\%) patients were assessable for COX-2 scoring. Overall COX-2 staining was seen in all tumor cores $(100 \%)$. Cytoplasmic COX-2 staining was high in $39(26.5 \%)$ tumors and low in $108(73.5 \%)$ tumors (Fig. 1a, b). COX-2 staining was positively associated with lymph node metastases ( $p=.015$, Table 2$)$. Median CSS was 39.5 months in patients with low COX-2 expression $(95 \%$ CI 20.00-58.93) versus 21.0 months (95\% CI 17.96-24.00) in patients with high COX-2 expression ( $p=.022$; log rank, Fig. 2). High COX-2 expression was significantly and inversely associated with CSS (HR 1.70; 95\% CI 1.07-2.69; $p=.023$, Table 4). COX-2 expression was not associated with recurrence of disease $(p=.173$, Table 2$)$

\section{VEGF Expression}

VEGF evaluation was assessable in tumor cores of 143 $(92.9 \%)$ patients. Overall staining was seen in 90 (62.9\%) tumors. High cytoplasmic expression was seen in 77 $(53.8 \%)$ and low staining in $66(46.2 \%)$ of patients (Fig. 1c, d). VEGF expression positively correlated with tumor stage $(p=.000)$, presence of lymph node metastases $(p=.032)$ and a lymph node ratio of $>25 \%$ ( $p=.001$, Table 3$)$. In patients with lymph node metastases, VEGF was significantly associated with perinodal nodal extension ( $p=.024$, data not shown). Patients with high VEGF expression more frequently developed recurrence of disease ( $p=.004$, Table 3$)$. Patients with low VEGF expression had a median CSS of 59.5 months (95\% CI 0.00-153.03), whereas patients with high VEGF expression had a median CSS of 21.6 months (95\% CI 16.18-27.02; $p=.004$; log rank, Fig. 3). High VEGF expression was significantly associated with poor CSS (HR 1.90; 95\% CI 1.22-2.96; $p=.005$, Table 4).

\section{Correlation between COX-2 and VEGF}

Tumor cores of $143(92.9 \%)$ patients were assessable for combined evaluation of VEGF and COX-2 staining. There was no significant correlation between VEGF and COX-2 expression $(r=.063 ; p=.455)$.

\section{Multivariate Analysis}

In multivariate analysis, high COX-2 expression was not associated with poor CSS (HR 1.55; 95\% CI 0.95-2.53; $p=.081$, Table 4). For OS, high COX-2 expression was an independent prognostic factor (HR 1.65; 95\% CI $1.04-2.61 ; p=.034$, Table 5). VEGF expression was not independently associated with CSS (HR 0.88; 95\%
Fig. 1 Representative examples of COX-2 and VEGF staining. a Tumor core showing strong (3+) cytoplasmic and granular COX-2 staining. Stromal tumor cells did not or only slightly stain positive for COX2. Original magnification $(\times 200)$. b Magnification $(\times 400)$ of tumor core shown in a. c Tumor core showing moderate cytoplasmic VEGF staining (2 $+)$. Original magnification $(\times 200)$. d Tumor cells showing weak cytoplasmic VEGF staining (1+). Original magnification $(\times 200)$

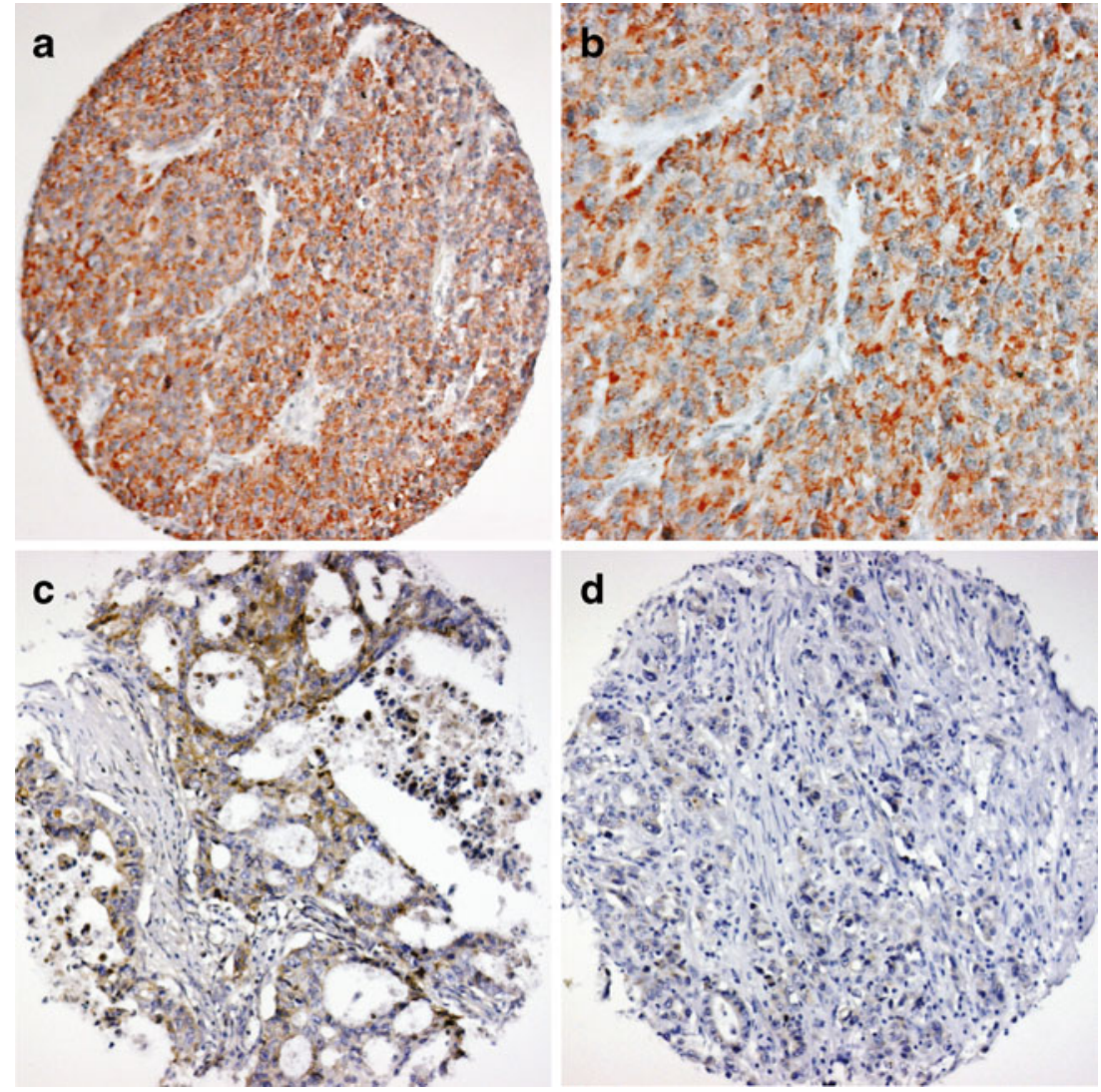


Table 2 Correlation of COX-2 expression and clinical and pathological parameters

\begin{tabular}{|c|c|c|c|c|}
\hline & \multirow[t]{2}{*}{ Total $(n)$} & \multicolumn{2}{|c|}{ COX-2 expression } & \multirow[t]{2}{*}{$p$ value } \\
\hline & & Low $(\%)$ & High $(\%)$ & \\
\hline Total $^{\mathrm{a}}$ & 147 & 73.5 & 26.5 & - \\
\hline \multicolumn{5}{|l|}{ Gender } \\
\hline Male & 121 & 76.0 & 24.0 & \multirow[t]{2}{*}{.129} \\
\hline Female & 26 & 61.5 & 38.5 & \\
\hline \multicolumn{5}{|c|}{ Median age } \\
\hline$<64$ years & 72 & 75.0 & 25.0 & \multirow[t]{2}{*}{.680} \\
\hline$\geq 64$ years & 75 & 72.0 & 28.0 & \\
\hline \multicolumn{5}{|c|}{ Pathological data } \\
\hline \multicolumn{5}{|l|}{ T-stage } \\
\hline $\mathrm{T} 1$ or $\mathrm{T} 2$ & 46 & 82.6 & 17.4 & \multirow[t]{2}{*}{.090} \\
\hline $\mathrm{T} 3$ & 101 & 69.3 & 30.7 & \\
\hline \multicolumn{5}{|c|}{ Tumor differentiation } \\
\hline $\mathrm{G} 1$ or $\mathrm{G} 2$ & 55 & 72.7 & 27.3 & \multirow[t]{2}{*}{1.000} \\
\hline G3 & 88 & 72.7 & 27.3 & \\
\hline \multicolumn{5}{|c|}{ Vasoinvasion } \\
\hline Yes & 69 & 75.4 & 24.6 & \multirow[t]{2}{*}{.625} \\
\hline No & 78 & 71.8 & 28.2 & \\
\hline \multicolumn{5}{|c|}{ Perineural growth } \\
\hline Yes & 43 & 65.1 & 34.9 & \multirow[t]{2}{*}{.149} \\
\hline No & 103 & 76.7 & 23.3 & \\
\hline \multicolumn{5}{|c|}{ LNN metastases } \\
\hline Yes & 102 & 68.6 & 31.4 & \multirow[t]{2}{*}{.015} \\
\hline No & 42 & 88.1 & 11.9 & \\
\hline \multicolumn{5}{|l|}{$\mathrm{LNN}$ ratio } \\
\hline$\leq 25 \%$ & 96 & 78.1 & 21.9 & \multirow[t]{2}{*}{.138} \\
\hline$>25 \%$ & 48 & 66.7 & 33.3 & \\
\hline \multicolumn{5}{|c|}{ Follow-up data } \\
\hline \multicolumn{5}{|c|}{ Recurrence and/or metastases } \\
\hline Yes & 88 & 69.3 & 30.7 & \multirow[t]{2}{*}{.173} \\
\hline No & 50 & 80.0 & 20.0 & \\
\hline \multicolumn{5}{|c|}{ Locoregional recurrence } \\
\hline Yes $^{c}$ & 31 & 74.2 & 25.8 & \multirow[t]{2}{*}{.541} \\
\hline No & 50 & 80.0 & 20.0 & \\
\hline \multicolumn{5}{|c|}{ Distant metastases } \\
\hline $\mathrm{Yes}^{\mathrm{c}}$ & 75 & 68.0 & 32.0 & \multirow[t]{2}{*}{.140} \\
\hline No & 50 & 80.0 & 20.0 & \\
\hline
\end{tabular}

$L N N$ lymph nodes

${ }^{\text {a }}$ Tumor cores from 147 patients were assessable for COX-2 scoring (147 of $154,95.5 \%)$

${ }^{\mathrm{b}}$ Pearson Chi-square test

${ }^{\mathrm{c}}$ A proportion of patients $(n=18)$ experienced both locoregional and distant metastases

CI $0.54-1.42 ; p=.591$, Table 4) nor with OS (HR 1.05; 95\% CI $0.67-1.64 ; p=.848$, Table 5 ).

In the subset of patients with advanced disease (i.e., T3 tumors), COX-2 was an independent prognostic marker for CSS (HR 1.81; 95\% CI 1.10-2.95; $p=.019$, Table 6) as well
COX-2

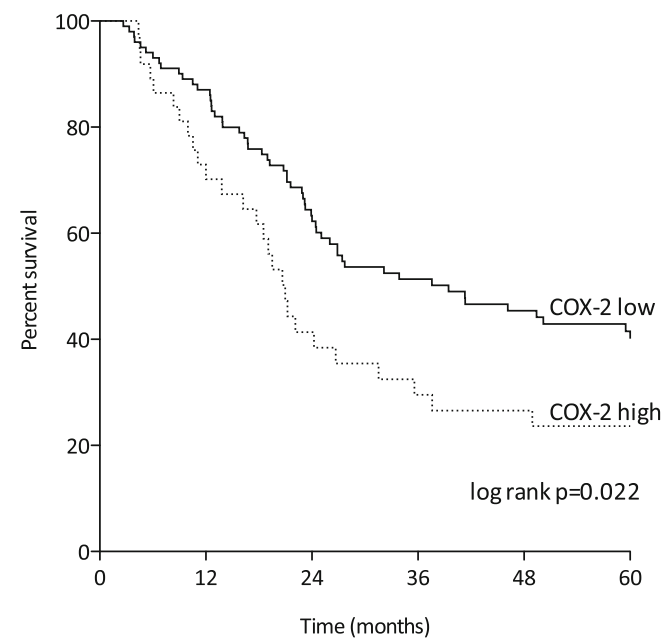

Fig. 2 Cancer specific survival according to high and low COX-2 staining. Log rank test was used to compare differences between survival curves

as for OS (HR 1.90; 95\% CI 1.18-3.05; $p=.008$, data not shown).

\section{Discussion}

This is the first study that evaluated the prognostic value and interaction of COX-2 and VEGF expression in a large and homogenous population of patients with EAC. Patients who received neo-adjuvant treatment or patients with $\mathrm{T} 4$ disease, distant metastases at time of operation, and tumor positive resection margins were excluded.

The Prognostic Value of COX-2 and VEGF Overexpression

The results showed high COX-2 and VEGF expression in $39(26.5 \%)$ and in $77(53.8 \%)$ of patients. Both were significantly associated with poor CSS $(p=.022$ and $p=.004$, respectively, log rank). In addition, COX-2 was independently associated with poor OS. In patients with advanced disease (T3), COX-2 was also an independent prognostic marker for CSS. This suggests that COX-2 is particularly of prognostic significance for patients with advanced disease.

Other studies have also identified COX-2 expression as an independent prognostic factor in $\mathrm{EAC}^{14,26,27}$ and in ESCC. ${ }^{28}$ Some authors have reported an independent prognostic significance of VEGF overexpression in ESCC, ${ }^{29-31}$ whereas other studies could not find any association between VEGF expression and survival in $\mathrm{EAC}^{32}$ and ESCC. ${ }^{33-35}$ In EAC, only one study has showed the independent prognostic value of VEGF overexpression. ${ }^{18}$

Some important limitations of these studies must be mentioned. Buskens et al., Takatori et al., Saad et al., and 
Table 3 Correlation of VEGF expression and clinical and pathological parameters

\begin{tabular}{|c|c|c|c|c|}
\hline & \multirow[t]{2}{*}{ Total $(n)$} & \multicolumn{2}{|c|}{ VEGF expression } & \multirow[t]{2}{*}{$p$ value } \\
\hline & & Low $(\%)$ & High $(\%)$ & \\
\hline Total $^{\mathrm{a}}$ & 143 & 46.2 & 53.8 & - \\
\hline \multicolumn{5}{|l|}{ Gender } \\
\hline Male & 117 & 44.4 & 55.6 & \multirow[t]{2}{*}{.384} \\
\hline Female & 26 & 53.8 & 46.2 & \\
\hline \multicolumn{5}{|c|}{ Median age } \\
\hline$<64$ years & 71 & 49.3 & 50.7 & \multirow[t]{2}{*}{.454} \\
\hline$\geq 64$ years & 72 & 43.1 & 56.9 & \\
\hline \multicolumn{5}{|l|}{ T-stage } \\
\hline $\mathrm{T} 1$ or $\mathrm{T} 2$ & 44 & 72.7 & 27.3 & \multirow[t]{2}{*}{.000} \\
\hline $\mathrm{T} 3$ & 99 & 34.3 & 65.7 & \\
\hline \multicolumn{5}{|c|}{ Tumor differentiation } \\
\hline $\mathrm{G} 1$ or $\mathrm{G} 2$ & 52 & 53.8 & 46.2 & \multirow[t]{2}{*}{.090} \\
\hline G3 & 87 & 39.1 & 60.9 & \\
\hline \multicolumn{5}{|c|}{ Vasoinvasion } \\
\hline Yes & 68 & 38.2 & 61.8 & \multirow[t]{2}{*}{.071} \\
\hline No & 75 & 53.3 & 46.7 & \\
\hline \multicolumn{5}{|c|}{ Perineural growth } \\
\hline Yes & 41 & 43.9 & 56.1 & \multirow[t]{2}{*}{.695} \\
\hline No & 101 & 47.5 & 52.5 & \\
\hline \multicolumn{5}{|c|}{ LNN metastases } \\
\hline Yes & 100 & 40.0 & 60.0 & \multirow[t]{2}{*}{.032} \\
\hline No & 40 & 60.0 & 40.0 & \\
\hline \multicolumn{5}{|l|}{$\mathrm{LNN}$ ratio } \\
\hline$\leq 25 \%$ & 93 & 55.9 & 44.1 & \multirow{2}{*}{.001} \\
\hline$>25 \%$ & 47 & 25.5 & 74.5 & \\
\hline \multicolumn{5}{|c|}{ Follow-up data } \\
\hline \multicolumn{5}{|c|}{ Recurrence and/or metastases } \\
\hline Yes & 87 & 35.6 & 64.4 & \multirow[t]{2}{*}{.004} \\
\hline No & 47 & 61.7 & 38.3 & \\
\hline \multicolumn{5}{|c|}{ Locoregional recurrence } \\
\hline $\mathrm{Yes}^{\mathrm{c}}$ & 30 & 26.7 & 73.3 & \multirow[t]{2}{*}{.003} \\
\hline No & 47 & 61.7 & 38.3 & \\
\hline \multicolumn{5}{|c|}{ Distant metastases } \\
\hline $\mathrm{Yes}^{\mathrm{c}}$ & 75 & 37.3 & 62.7 & \multirow[t]{2}{*}{.009} \\
\hline No & 47 & 61.7 & 38.3 & \\
\hline
\end{tabular}

$L N N$ lymph nodes

${ }^{\text {a }}$ Tumor cores from 143 patients were assessable for VEGF scoring (143 of $154: 92.9 \%)$

${ }^{\mathrm{b}}$ Pearson chi-square test

${ }^{\mathrm{c}}$ A proportion of patients $(n=18)$ experienced both locoregional and distant metastases

Ogata et al. included patients who had distant metastases at time of resection, which was seen in $19 \%(28 / 145), 33 \%$ $(75 / 228), 40 \%(30 / 75)$, and in $24 \%(22 / 92)$ of cases, respectively. ${ }^{14,18,28,31}$ In addition, the series of Buskens et al. included 33 of 145 (23\%) patients with a positive resection margin. ${ }^{14}$ Patients with distant metastases and positive

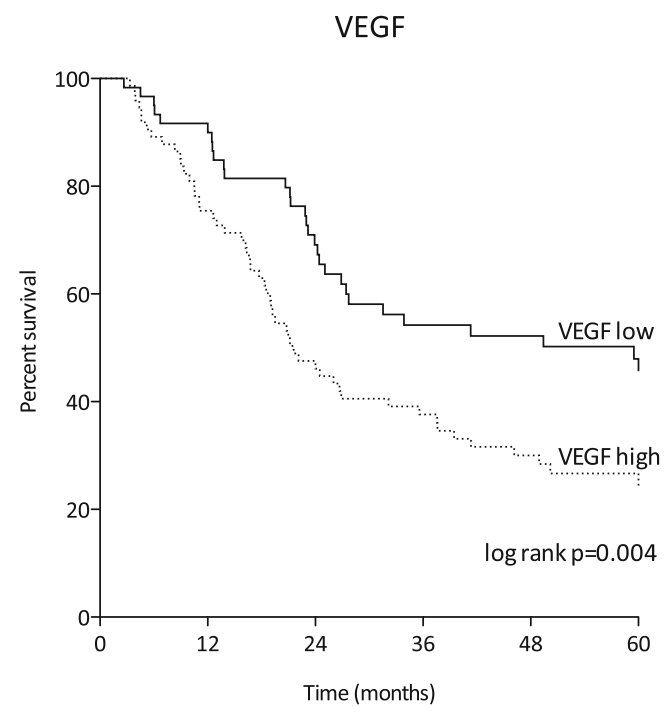

Fig. 3 Cancer specific survival according to high and low VEGF staining. Log rank test was used to compare differences between survival curves

resection margins have poor prognosis irrespective of COX2 expression. The inclusion of such cases greatly affects the survival rate of the studied population, making it difficult to interpret the correlation between protein expression and prognosis. Furthermore, many of these studies analyzed OS instead of CSS. ${ }^{14,26,27}$

\section{Correlation between COX-2 and VEGF Expression}

COX-2 and VEGF both play an important role in carcinogenesis, tumor progression, and angiogenesis. In the studied cohort, we did not observe a correlation between VEGF and COX-2 expression $(r=.063 ; p=.455)$. Other studies with varying population size, patient selection, and methodology reported otherwise and suggest that the two markers are interlinked. ${ }^{23,36,37}$

Vallböhmer et al. $(n=75)$ and von Rahden et al. $(n=123)$ evaluated the quantity of VEGF and COX-2 messenger RNA in EAC using quantitative reverse transcription polymerase chain reaction (qRT-PCR). Both authors reported a significant correlation between COX-2 and VEGF $(r=.460$, $p<.001$ and $r=.764, p<.001$, respectively). ${ }^{23,36}$ However, Vallböhmer et al. investigated a mixed population (16 patients with ESCC, 15 with Barrett's esophagus, and 44 with EAC) and found that COX-2 and VEGF expressions were only correlated when the overall study population was analyzed. $^{36}$

In another study of 40 patients with ESCC, a significant correlation between high COX-2 $(65.4 \%)$ and VEGF $(50 \%)$ expression $(p<.005)$ was reported using immunohistochemistry (IHC) ${ }^{37}$ The study included patients who received neoadjuvant therapy before surgery. Pathological 
Table 4 Univariate and multivariate analysis of associations between histopathologic parameters and cancer specific survival (CSS)

\begin{tabular}{|c|c|c|c|c|c|c|}
\hline & \multicolumn{2}{|c|}{ Median CSS in months } & \multirow{2}{*}{$\begin{array}{l}\text { Unadjusted HR }(95 \% \mathrm{CI}) \\
\text { Univariate }\end{array}$} & \multirow[t]{2}{*}{$p$ value } & \multirow{2}{*}{$\begin{array}{l}\text { Adjusted HR }(95 \% \mathrm{CI})^{\mathrm{a}} \\
\text { Multivariate }\end{array}$} & \multirow[t]{2}{*}{$p$ value } \\
\hline & Negative & Positive & & & & \\
\hline Perinodal extension $^{\mathrm{c}}$ & 26.9 & 20.7 & $1.864(1.160-2.995)$ & .010 & & \\
\hline Gender (male/female) & 32.2 & 26.7 & $1.050(0.592-1.860)$ & .868 & & \\
\hline Median age $(<64 / \geq 64$ years $)$ & 24.5 & 37.6 & $1.001(0.657-1.525)$ & .998 & & \\
\hline $\mathrm{T}$ stage $(\mathrm{T} 1, \mathrm{~T} 2 / \mathrm{T} 3)$ & $\mathrm{b}$ & 22.9 & $10.282(4.441-23.807)$ & .000 & $3.833(1.404-10.468)$ & .009 \\
\hline Positive lymph nodes & $\mathrm{b}$ & 23.2 & $6.595(3.166-13.740)$ & .000 & $2.338(0.979-5.587)$ & .056 \\
\hline $\mathrm{G}$ grade $(\mathrm{G} 1, \mathrm{G} 2 / \mathrm{G} 3)^{\mathrm{d}}$ & 127.9 & 21.2 & $2.952(1.809-4.817)$ & .000 & $2.103(1.214-3.644)$ & .008 \\
\hline $\mathrm{LNN}$ ratio $(\leq 0.25 />25)$ & 64.3 & 18.5 & $3.832(2.194-5.213)$ & .000 & $1.595(0.943-2.698)$ & .082 \\
\hline COX-2 (low/high) & 39.4 & 21.0 & $1.698(1.074-2.685)$ & .023 & $1.546(0.947-2.525)$ & .081 \\
\hline Vasoinvasion & $\mathrm{b}$ & 21.6 & $3.283(2.107-5.116)$ & .000 & $1.538(0.901-2.623)$ & .114 \\
\hline Perineural growth & 49.4 & 21.2 & $2.532(1.633-3.927)$ & .000 & $1.142(0.705-1.851)$ & .589 \\
\hline VEGF (low/high) & 59.5 & 21.6 & $1.897(1.216-2.959)$ & .005 & $0.877(0.544-1.415)$ & .591 \\
\hline
\end{tabular}

$L N N$ lymph nodes, $C I$ confidence interval

${ }^{\text {a }}$ Multivariate analysis was carried out with variables proven significant in univariate analysis

${ }^{\mathrm{b}}$ Median survival was not determined, since expected cumulative survival within the study period did not reach $50 \%$

${ }^{\mathrm{c}}$ As a proportion of patients with positive lymph nodes $(n=100)$. Perinodal extension was not included in multivariate analysis

${ }^{\mathrm{d}} \mathrm{G}$ grade indicates tumor differentiation

complete response (i.e., the absence of visible tumor cells) was seen in $35 \%$ of patients. The evaluation of tumor specific protein expression in specimens without visible tumor cells is questionable. However, these specimens were considered as negative staining for both COX-2 and VEGF. This increased the proportion of VEGF and COX-2 co-expression (i.e., negative staining).
Relationship of COX-2 and VEGF Expression and Clinical and Pathological Parameters

Analysis of (linear) relationships between COX-2 expression and prognostic parameters showed a significant correlation between high COX-2 expression and the presence of lymph node metastases. This is consistent with previous

Table 5 Univariate and multivariate analysis of associations between histopathologic parameters and overall survival (OS)

\begin{tabular}{|c|c|c|c|c|c|c|}
\hline & \multicolumn{2}{|c|}{ Median OS in months } & \multirow{2}{*}{$\begin{array}{l}\text { Unadjusted HR }(95 \% \mathrm{CI}) \\
\text { Univariate }\end{array}$} & \multirow[t]{2}{*}{$p$ value } & \multirow{2}{*}{$\begin{array}{l}\text { Adjusted HR }(95 \% \mathrm{CI})^{\mathrm{a}} \\
\text { Multivariate }\end{array}$} & \multirow[t]{2}{*}{$p$ value } \\
\hline & Negative & Positive & & & & \\
\hline Perinodal extension ${ }^{\mathrm{b}}$ & 26.7 & 19.2 & $1.736(1.108-2.722)$ & .016 & & \\
\hline Gender (male/female) & 24.0 & 29.0 & $1.120(0.674-1.860)$ & .661 & & \\
\hline Median age $(<64 / \geq 64 \mathrm{Y})$ & 24.4 & 27.4 & $1.319(0.899-1.934)$ & .157 & & \\
\hline T stage (T1,T2/T3) & 196.1 & 21.2 & $5.537(3.148-9.736)$ & .000 & $2.974(1.390-6.364)$ & .005 \\
\hline $\mathrm{G}$ grade $(\mathrm{G} 1, \mathrm{G} 2 / \mathrm{G} 3)^{\mathrm{c}}$ & 64.3 & 19.5 & $2.864(1.846-4.443)$ & .000 & $2.218(1.342-3.665)$ & .002 \\
\hline COX-2 (low/high) & 29.1 & 19.5 & $1.732(1.138-2.636)$ & .010 & $1.645(1.037-2.607)$ & .034 \\
\hline Vasoinvasion & 61.6 & 21.2 & $2.635(1.771-3.922)$ & .000 & $1.458(0.897-2.367)$ & .128 \\
\hline Positive lymph nodes & 193.1 & 22.9 & $3.585(2.130-6.034)$ & .000 & $1.393(0.730-2.657)$ & .314 \\
\hline $\mathrm{LNN}$ ratio $(\leq 0.25 />25)$ & 48.9 & 18.3 & $2.592(1.735-3.873)$ & .000 & $1.355(0.827-2.221)$ & .228 \\
\hline Perineural growth & 39.4 & 21.0 & $2.333(1.536-3.543)$ & .000 & $1.139(0.714-1.815)$ & .585 \\
\hline VEGF (low/high) & 41.3 & 21.0 & $1.945(1.295-2.920)$ & .001 & $1.045(0.667-1.636)$ & .848 \\
\hline
\end{tabular}

LNN lymph nodes, $C I$ confidence interval

${ }^{\text {a }}$ Multivariate analysis was carried out with variables proven significant in univariate analysis

${ }^{\mathrm{b}}$ As a proportion of patients with positive lymph nodes $(n=100)$. Perinodal extension was not included in multivariate analysis

${ }^{\mathrm{c}} \mathrm{G}$ grade indicates tumor differentiation 
Table 6 Univariate and multivariate analysis of associations between histopathologic parameters and cancer specific survival (CSS) in T3 tumors $(n=100)$

\begin{tabular}{|c|c|c|c|c|c|c|}
\hline & \multicolumn{2}{|c|}{ Median CSS in months } & \multirow{2}{*}{$\begin{array}{l}\text { Unadjusted HR }(95 \% \mathrm{CI}) \\
\text { Univariate }\end{array}$} & \multirow[t]{2}{*}{$p$ value } & \multirow{2}{*}{$\begin{array}{l}\text { Adjusted HR }(95 \% \mathrm{CI})^{\mathrm{a}} \\
\text { Multivariate }\end{array}$} & \multirow[t]{2}{*}{$p$ value } \\
\hline & Negative & Positive & & & & \\
\hline Gender (male/female) & 23.2 & 16.4 & $1.461(0.818-2.608)$ & .200 & & \\
\hline Perineural growth & 23.2 & 21.2 & $1.387(0.887-2.169)$ & .151 & & \\
\hline Perinodal extension ${ }^{\mathrm{b}}$ & 24.0 & 20.7 & $1.261(0.775-2.052)$ & .350 & & \\
\hline VEGF (low/high) & 23.9 & 21.0 & $1.056(0.665-1.677)$ & .819 & & \\
\hline Median age $(<64 / \geq 64$ years $)$ & 22.1 & 24.0 & $1.012(0.653-1.567)$ & .959 & & \\
\hline $\mathrm{G}$ grade $(\mathrm{G} 1, \mathrm{G} 2 / \mathrm{G} 3)^{\mathrm{c}}$ & 37.6 & 19.1 & $2.335(1.373-3.971)$ & .002 & $2.017(1.159-3.511)$ & .013 \\
\hline COX-2 (low/high) & 24.4 & 19.1 & $1.769(1.099-2.847)$ & .019 & $1.805(1.103-2.954)$ & .019 \\
\hline Positive lymph nodes & 41.3 & 22.9 & $2.200(1.005-4.816)$ & .048 & $1.822(0.789-4.209)$ & .160 \\
\hline Vasoinvasion & 26.9 & 20.7 & $2.020(1.278-3.195)$ & .003 & $1.640(0.963-2.791)$ & .068 \\
\hline $\mathrm{LNN}$ ratio $(\leq 0.25 />25)$ & 26.7 & 18.5 & $2.226(1.420-3.488)$ & .000 & $1.453(0.859-2.458)$ & .163 \\
\hline
\end{tabular}

$L N N$ lymph nodes, $C I$ confidence interval

${ }^{\text {a }}$ Multivariate analysis was carried out with variables proven significant in univariate analysis

${ }^{\mathrm{b}}$ As a proportion of patients with positive lymph nodes $(n=88)$

${ }^{\mathrm{c}} \mathrm{G}$ grade indicates tumor differentiation

studies. ${ }^{27,37,38}$ High VEGF expression was significantly correlated with depth of tumor invasion (T-stage), presence of lymph node metastases, lymph node ratio, and perinodal growth. In addition, expression was associated with recurrence of disease. This is also consistent with previous studies which describe a correlation between VEGF and T-stage, ${ }^{18,29,35,39,40}$ lymph node metastases, ${ }^{18,39-43}$ and recurrence of disease. ${ }^{18,29}$

COX-2 and VEGF expression were both associated with lymphatic tumor metastases. A possible explanation might be found in the involvement of HIF- $1 \alpha$, which is an important transcription factor regulating transcription of genes that are involved in metastatic spreading of disease. COX-2 and VEGF are target genes of HIF- $1 \alpha$ and are both responsible for vasodilation, increased vessel permeability, and tumor cell invasion. We hypothesize that COX-2 and VEGF both lead to vasodilatation of lymphatic vessels leading to increased microvascular permeability. The leaky state of microvessels causes extravasation of tissue metalloproteinase, which is also induced by COX- 2 and VEGF. ${ }^{44,45}$ This causes degradation of the extracellular matrix, further facilitating invasion of cancer cells into the lymphatic vessels. Furthermore, VEGF-induced metalloproteinases may lead to degradation of basement membrane and therefore to higher T-stage (i.e., depth of tumor invasion). Again, this is hypothetical and requires investigation in future studying.

Evaluation of COX-2 and VEGF Expression

Using Immunohistochemistry (IHC)

Reported rates of high VEGF and COX-2 protein expression in esophageal cancer vary widely from $25 \%$ to $91 \%$ for COX-
$2^{13,14,46}$ and $24 \%$ to $80 \%$ for VEGF expression. ${ }^{13,18,30,35,40,42}$ This variation is mostly due to differences in patient selection (e.g., inclusion of patients with both ESCC and EAC, with distant metastases, or positive resection margins) and methodology (e.g., the use of different cutoff values, reagents, or scoring methods).

It might be argued that evaluation of messenger RNA expression with qRT-PCR and Northern blot techniques provides a more objective analysis of COX-2 and VEGF expression. However, IHC is the most frequently used and most reliable method today for analyzing protein expression from formalin-fixed and paraffin-embedded material. IHC is still the gold standard to evaluate tumor marker expression for diagnostic purposes. Moreover, a major advantage of IHC above other techniques is that it enables precise location of the (increased) signal within the tumor cell. With techniques that evaluate messenger RNA expression the histology of the tumor is no longer available. These techniques may overestimate COX-2 and VEGF expression because non-cancerous tissues such as inflammatory cells and vascular endothelial cells (that also express high levels COX-2 and VEGF) are included in the sample.

Targeted Therapies with COX-2 and VEGF Inhibitors

The results showed that COX-2 and VEGF expression were both associated with poor survival. Therefore, specific inhibition of these pathways may affect prognosis. To date, several trials have been conducted with VEGF inhibitors such as monoclonal antibody bevacizumab or tyrosine 
kinase inhibitors like sorafenib. ${ }^{47-49}$ Other trials included COX-2 specific inhibitors such as celecoxib. ${ }^{22,50,51}$

Two phase I-II trials, applying chemoradiotherapy (cisplatin, fluorouracil) added with celecoxib, report clinical complete response 7 of 13 patients (54\%) and pathological complete response in 5 of 22 patients (22\%), respectively. ${ }^{50,51}$ Furthermore, Tuynman et al. reported significant COX-2 downregulation in patients who underwent neoadjuvant celecoxib treatment $(p<.010){ }^{22}$ Although concerns exist about longterm usage of COX-2 inhibitors with regard to its potential cardiovascular risk, ${ }^{52}$ in all studies celecoxib was accompanied with acceptable toxicities without cardiovascular events.

A phase II study combining chemotherapy (irinotecan and cisplatin) with bevacizumab treatment in 34 patients resulted in an overall response rate (i.e., complete and partial response) of $65 \%$ (complete pathologic response in $6 \%$ ). ${ }^{47}$ Another phase II study, which combined doxetaxel and cisplatin with sorafenib, yielded $41 \%$ partial response (complete response in $0 \%) .{ }^{48}$ A phase II study with doxetaxel, cisplatin, and fluorouracil added with bevacizumab $(n=39)$ showed a response rate of $67 \%$ (complete response in $5 \%$ ). ${ }^{49}$ These results support the use of VEGF and COX-2 inhibitors in future studies. Combining the inhibitors could possibly show synergistic effects, ultimately benefitting patients' prognosis.

\section{Future Perspectives}

At present, all patients receive neoadjuvant treatment. Therefore, it is not possible to validate the prognostic value of COX-2 and VEGF expression in a prospective cohort. However, it would be of great value to prospectively evaluate COX-2 and VEGF expression in pre-treatment biopsies. Using this method, correlation between COX-2 and VEGF expression and response to neoadjuvant treatment can be evaluated. When patients are not expected to benefit from adjuvant therapy, surgery could be rescheduled accordingly to prevent further progression of disease.

In conclusion, the results show high COX-2 in a quarter of EAC patients and high VEGF expression in over half of EAC patients. Both markers were associated with poor prognosis. Moreover, COX-2 was an independent prognostic marker for survival. Although a relationship between COX-2 and VEGF expression could not be identified, the findings support the use of COX-2 and VEGF inhibitors in future clinical studies.

Conflicts of Interest and Sources of Funding None of the authors have a financial relationship with a commercial entity that has an interest in the subject of this manuscript. No funding was received for this study.

Author Contributions All authors contributed equally to the study.
Open Access This article is distributed under the terms of the Creative Commons Attribution Noncommercial License which permits any noncommercial use, distribution, and reproduction in any medium, provided the original author(s) and source are credited.

\section{References}

1. Jemal A, Siegel R, Xu J, Ward E. Cancer statistics, 2010. CA Cancer J. Clin. 2010;60:277-300.

2. Cunningham D, Allum WH, Stenning SP, Thompson JN, van de Velde CJ, Nicolson M, Scarffe JH, Lofts FJ, Falk SJ, Iveson TJ, Smith DB, Langley RE, Verma M, Weeden S, Chua YJ, MAGIC Trial Participants. Perioperative chemotherapy versus surgery alone for resectable gastroesophageal cancer. N.Engl.J.Med. 2006;355:11-20.

3. Omloo JM, Lagarde SM, Hulscher JB, Reitsma JB, Fockens P, van Dekken H, ten Kate FJW, Obertop H, Tilanus HW, Van Lanschot JJ. Extended transthoracic resection compared with limited transhiatal resection for adenocarcinoma of the mid/distal esophagus: five-year survival of a randomized clinical trial. Ann.Surg. 2007;246:992-1000.

4. van Meerten E, Muller K, Tilanus HW, Siersema PD, Eijkenboom WM, van Dekken H, Tran TC, van der Gaast A. Neoadjuvant concurrent chemoradiation with weekly paclitaxel and carboplatin for patients with oesophageal cancer: a phase II study. Br.J.Cancer 2006;94:1389-1394.

5. Aklilu M, Ilson DH. Targeted agents and esophageal cancer-the next step? Semin.Radiat.Oncol. 2007;17:62-69.

6. Hanahan D, Weinberg RA. Hallmarks of cancer: the next generation. Cell 2011;144:646-674.

7. Tew WP, Kelsen DP, Ilson DH. Targeted therapies for esophageal cancer. Oncologist. 2005;10:590-601.

8. Ogino S, Kirkner GJ, Nosho K, Irahara N, Kure S, Shima K, Hazra A, Chan AT, Dehari R, Giovannucci EL, Fuchs CS. Cyclooxygenase-2 expression is an independent predictor of poor prognosis in colon cancer. Clin. Cancer Res. 2008;14:8221-8227.

9. Lim HY, Joo HJ, Choi JH, Yi JW, Yang MS, Cho DY, Kim HS, Nam DK, Lee KB, Kim HC. Increased expression of cyclooxygenase-2 protein in human gastric carcinoma. Clin. Cancer Res. 2000;6: 519-525.

10. Matsubayashi H, Infante JR, Winter J, Klein AP, Schulick R, Hruban R, Visvanathan K, Goggins M. Tumor COX-2 expression and prognosis of patients with resectable pancreatic cancer. Cancer Biol. Ther. 2007;6:1569-1575.

11. Wu YC, Su LJ, Wang HW, Jeff Lin CF, Hsu WH, Chou TY, Huang CY, Lu CL, Hsueh CT. Co-overexpression of cyclooxygenase-2 and microsomal prostaglandin E synthase-1 adversely affects the postoperative survival in non-small cell lung cancer. J.Thorac. Oncol. 2010;5:1167-1174.

12. Barisik NO, Keser SH, Gul AE, Sensu S, Kandemir NO, Kucuk HF, Gumus M, Karadayi N. The value of COX-2 expression in the prognostic parameters of invasive ductal carcinoma of the breast. Med. Oncol. 2010;28:703-708.

13. Boone J, van Hillegersberg R, Offerhaus GJ, van Diest PJ, Borel Rinkes IHM, ten Kate FJW. Targets for molecular therapy in esophageal squamous cell carcinoma: an immunohistochemical analysis. Dis. Esophagus. 2009;22:496-504.

14. Buskens CJ, Van Rees BP, Sivula A, Reitsma JB, Haglund C, Bosma PJ, Offerhaus GJ, Van Lanschot JJ, Ristimaki A. Prognostic significance of elevated cyclooxygenase 2 expression in patients with adenocarcinoma of the esophagus. Gastroenterology 2002;122:1800-1807.

15. Kleespies A, Bruns CJ, Jauch KW. Clinical significance of VEGFA, $-\mathrm{C}$ and $-\mathrm{D}$ expression in esophageal malignancies. Onkologie. 2005;28:281-288. 
16. Donnem T, Al-Shibli K, Andersen S, Al-Saad S, Busund LT, Bremnes RM. Combination of low vascular endothelial growth factor A (VEGF-A)/VEGF receptor 2 expression and high lymphocyte infiltration is a strong and independent favorable prognostic factor in patients with nonsmall cell lung cancer. Cancer 2010;116:4318-4325.

17. Patard JJ, Rioux-Leclercq N, Masson D, Zerrouki S, Jouan F, Collet N, Dubourg C, Lobel B, Denis M, Fergelot P. Absence of VHL gene alteration and high VEGF expression are associated with tumour aggressiveness and poor survival of renal-cell carcinoma. Br. J. Cancer 2009;101:1417-1424.

18. Saad RS, El-Gohary Y, Memari E, Liu YL, Silverman JF. Endoglin (CD105) and vascular endothelial growth factor as prognostic markers in esophageal adenocarcinoma. Hum. Pathol. 2005;36:955-961.

19. Wu Y, Jin M, Xu H, Shimin Z, He S, Wang L, Zhang Y. Clinicopathologic significance of HIF-1alpha, CXCR4, and VEGF expression in colon cancer. Clin. Dev. Immunol. 2010;2010:

20. Masferrer JL, Leahy KM, Koki AT, Zweifel BS, Settle SL, Woerner BM, Edwards DA, Flickinger AG, Moore RJ, Seibert $\mathrm{K}$. Antiangiogenic and antitumor activities of cyclooxygenase-2 inhibitors. Cancer Res. 2000;60:1306-1311.

21 . Gately S. The contributions of cyclooxygenase- 2 to tumor angiogenesis. Cancer Metastasis Rev. 2000;19:19-27.

22. Tuynman JB, Buskens CJ, Kemper K, ten Kate FJW, Offerhaus GJ, Richel DJ, Van Lanschot JJ. Neoadjuvant selective COX-2 inhibition down-regulates important oncogenic pathways in patients with esophageal adenocarcinoma. Ann. Surg. $2005 ; 242: 840-9$.

23. von Rahden BH, Stein HJ, Puhringer F, Koch I, Langer R, Piontek G, Siewert JR, Hofler H, Sarbia M. Coexpression of cyclooxygenases (COX-1, COX-2) and vascular endothelial growth factors (VEGF-A, VEGF-C) in esophageal adenocarcinoma. Cancer Res. 2005;65:5038-5044.

24. Verhage RJ, Zandvoort HJ, ten Kate FJ, van Hillegersberg R. How to define a positive circumferential resection margin in T3 adenocarcinoma of the esophagus. Am. J. Surg. Pathol. 2011;35:919926.

25. Edge SB, Byrd DR, Compton CC, Fritz AG, Greene FL, Trotti A. AJCC cancer staging manual (7th edition). 2010

26. Heeren P, Plukker J, van Dullemen H, Nap R, Hollema H. Prognostic role of cyclooxygenase-2 expression in esophageal carcinoma. Cancer Lett. 2005;225:283-289.

27. Bhandari P, Bateman AC, Mehta RL, Stacey BS, Johnson P, Cree IA, Di NF, Patel P. Prognostic significance of cyclooxygenase-2 (COX-2) expression in patients with surgically resectable adenocarcinoma of the oesophagus. BMC.Cancer 2006;6:134.

28. Takatori H, Natsugoe S, Okumura H, Matsumoto M, Uchikado Y, Setoyama T, Sasaki K, Tamotsu K, Owaki T, Ishigami S, Aikou T. Cyclooxygenase- 2 expression is related to prognosis in patients with esophageal squamous cell carcinoma. Eur. J. Surg. Oncol. 2008;34:397-402.

29. Inoue K, Ozeki Y, Suganuma T, Sugiura Y, Tanaka S. Vascular endothelial growth factor expression in primary esophageal squamous cell carcinoma. Association with angiogenesis and tumor progression. Cancer 1997;79:206-213.

30. Shih CH, Ozawa S, Ando N, Ueda M, Kitajima M. Vascular endothelial growth factor expression predicts outcome and lymph node metastasis in squamous cell carcinoma of the esophagus. Clin. Cancer Res. 2000;6:1161-1168.

31. Ogata Y, Fujita H, Yamana H, Sueyoshi S, Shirouzu K. Expression of vascular endothelial growth factor as a prognostic factor in node-positive squamous cell carcinoma in the thoracic esophagus: long-term follow-up study. World J. Surg. 2003;27:584-589.

32. Couvelard A, Paraf F, Gratio V, Scoazec JY, Henin D, Degott C, Flejou JF. Angiogenesis in the neoplastic sequence of Barrett's oesophagus. Correlation with VEGF expression. J.Pathol. 2000;192:14-18.

33. Ahn MJ, Jang SJ, Park YW, Choi JH, Oh HS, Lee CB, Paik HK, Park CK. Clinical prognostic values of vascular endothelial growth factor, microvessel density, and p53 expression in esophageal carcinomas. J. Korean Med. Sci. 2002;17:201-207.

34. Rosa AR, Schirmer CC, Gurski RR, Meurer L, Edelweiss MI, Kruel CD. Prognostic value of $\mathrm{p} 53$ protein expression and vascular endothelial growth factor expression in resected squamous cell carcinoma of the esophagus. Dis. Esophagus. 2003;16:112-118.

35. Lu CL, Ji Y, Ge D, Guo J, Ding JY. The expression of CXCR4 and its relationship with matrix metalloproteinase-9/vascular endothelial growth factor in esophageal squamous cell cancer. Dis. Esophagus. 2011;24:283-290.

36. Vallbohmer D, Peters JH, Kuramochi H, Oh D, Yang D, Shimizu D, DeMeester SR, Hagen JA, Chandrasoma PT, Danenberg KD, Danenberg PV, DeMeester TR. Molecular determinants in targeted therapy for esophageal adenocarcinoma. Arch. Surg. 2006;141:476-481.

37. Yoshikawa R, Fujiwara Y, Koishi K, Kojima S, Matsumoto T, Yanagi H, Yamamura T, Hashimoto-Tamaoki T, Nishigami T, Tsujimura T. Cyclooxygenase-2 expression after preoperative chemoradiotherapy correlates with more frequent esophageal cancer recurrence. World J. Gastroenterol. 2007;13:2283-2288.

38. Mobius C, Stein HJ, Spiess C, Becker I, Feith M, Theisen J, Gais $\mathrm{P}$, Jutting U, Siewert JR. COX2 expression, angiogenesis, proliferation and survival in Barrett's cancer. Eur. J. Surg. Oncol. 2005;31:755-759.

39. Kitadai Y, Haruma K, Tokutomi T, Tanaka S, Sumii K, Carvalho M, Kuwabara M, Yoshida K, Hirai T, Kajiyama G, Tahara E. Significance of vessel count and vascular endothelial growth factor in human esophageal carcinomas. Clin. Cancer Res. 1998;4:21952200.

40. Uchida S, Shimada Y, Watanabe G, Tanaka H, Shibagaki I, Miyahara $\mathrm{T}$, Ishigami S, Imamura M. In oesophageal squamous cell carcinoma vascular endothelial growth factor is associated with p53 mutation, advanced stage and poor prognosis. Br. J. Cancer 1998;77:17041709.

41. Sato F, Shimada Y, Watanabe G, Uchida S, Makino T, Imamura M. Expression of vascular endothelial growth factor, matrix metalloproteinase- 9 and E-cadherin in the process of lymph node metastasis in oesophageal cancer. Br. J. Cancer 1999;80:13661372.

42. Mukherjee T, Kumar A, Mathur M, Chattopadhyay TK, Ralhan R. Ets-1 and VEGF expression correlates with tumor angiogenesis, lymph node metastasis, and patient survival in esophageal squamous cell carcinoma. J. Cancer Res. Clin. Oncol. 2003;129:430 436.

43. Millikan KW, Mall JW, Myers JA, Hollinger EF, Doolas A, Saclarides TJ. Do angiogenesis and growth factor expression predict prognosis of esophageal cancer? Am. Surg. 2000;66:401-405.

44. Pufe T, Harde V, Petersen W, Goldring MB, Tillmann B, Mentlein R. Vascular endothelial growth factor (VEGF) induces matrix metalloproteinase expression in immortalized chondrocytes. J. Pathol. 2004;202:367-374.

45. Sivula A, Talvensaari-Mattila A, Lundin J, Joensuu H, Haglund C, Ristimaki A, Turpeenniemi-Hujanen T. Association of cyclooxygenase-2 and matrix metalloproteinase-2 expression in human breast cancer. Breast Cancer Res. Treat. 2005;89:215-220.

46. Sivula A, Buskens CJ, Van Rees BP, Haglund C, Offerhaus GJ, Van Lanschot JJ, Ristimaki A. Prognostic role of cyclooxygenase2 in neoadjuvant-treated patients with squamous cell carcinoma of the esophagus. Int. J. Cancer 2005;116:903-908.

47. Shah MA, Ramanathan RK, Ilson DH, Levnor A, D'Adamo D, O'Reilly E, Tse A, Trocola R, Schwartz L, Capanu M, Schwartz GK, Kelsen DP. Multicenter phase II study of irinotecan, 
cisplatin, and bevacizumab in patients with metastatic gastric or gastroesophageal junction adenocarcinoma. J. Clin. Oncol. 2006;24:5201-5206.

48. Sun W, Powell M, O'Dwyer PJ, Catalano P, Ansari RH, Benson AB3. Phase II study of sorafenib in combination with docetaxel and cisplatin in the treatment of metastatic or advanced gastric and gastroesophageal junction adenocarcinoma: ECOG 5203. J. Clin. Oncol. 2010;28:2947-2951.

49. Shah MA, Jhawer M, Ilson DH, Lefkowitz RA, Robinson E, Capanu M, Kelsen DP. Phase II study of modified docetaxel, cisplatin, and fluorouracil with bevacizumab in patients with metastatic gastroesophageal adenocarcinoma. J. Clin. Oncol. 2011;29:868-874.
50. Dawson SJ, Michael M, Biagi J, Foo KF, Jefford M, Ngan SY, Leong T, Hui A, Milner AD, Thomas RJ, Zalcberg JR. A phase I/II trial of celecoxib with chemotherapy and radiotherapy in the treatment of patients with locally advanced oesophageal cancer. Invest New Drugs 2007;25:123-129.

51. Govindan R, McLeod H, Mantravadi P, Fineberg N, Helft P, Kesler K, Hanna N, Stoner C, Ansari R, Fox E. Cisplatin, fluorouracil, celecoxib, and RT in resectable esophageal cancer: preliminary results. Oncology (Williston.Park) 2004;18:18-21.

52. Solomon SD, McMurray JJ, Pfeffer MA, Wittes J, Fowler R, Finn P, Anderson WF, Zauber A, Hawk E, Bertagnolli M. Cardiovascular risk associated with celecoxib in a clinical trial for colorectal adenoma prevention. N.Engl.J.Med. 2005;352:1071-1080. 